\title{
Changing Rationales for Computers in Education: from Liberation to Involvement
}

\author{
Steve Kennewell \\ Cardiff Metropolitan University, UK \\ skennewell@cardiffmet.ac.uk
}

\begin{abstract}
This paper examines the themes for two World Conferences on Computers in Education to characterize and theorize the shift in pedagogical rationale from 'liberating the learner' (the 1995 theme) to 'involving everyone' (the 2017 theme). The WCCE 1995 contributors' responses to the theme of liberation are analyzed in terms of how the affordances of digital technology for learning are orchestrated by teachers, students and the technology itself. The pedagogical effects of developments in the use of technology in education since 1995 are considered using four key examples, and WCCE 2017 contributors' responses to the theme of involvement are discussed in the context of these effects. The paper concludes that the shift from 'liberation' to 'involvement' represents a progression in expectations concerning how technology can aid learning, but that involvement requires that the learner should develop an intention to learn and an ability to orchestrate resources which teachers should help them to acquire.
\end{abstract}

Keywords. Rationale, liberation, involvement, affordance, orchestration

\section{Introduction}

The use of digital technology to enhance learning has a 50-year history, and it is right that our current exploits should build on what has gone before. However, not only has the power of the technology changed considerably over the years, but the pedagogical rationale for its use has also shifted - albeit more subtly. These changes have implications for our research strategies and for the theories which underpin the application of technology to teaching and learning. As an example of this, I want to start by recalling WCCE 1995, whose theme was 'Liberating the Learner'. I am going to examine the meaning of this idea in general terms, then analyse how it was interpreted in 1995. I will next consider what we have learned about learner liberation through the use of digital technology during the intervening 22 years. Finally, I will discuss how the WCCE 2017 theme of 'Involving everyone' can be enriched by this reflection.

Liberty can take the form of freedom from prohibitions or restrictions, or of freedom to act as desired. Proposing (greater) liberty for the learner therefore raises question of what constraints are being relaxed, what actions are being allowed or facilitated in contexts where learning is expected, and what advantages these changes provide for the learner. 
The purpose of educational systems - primary schools, secondary schools of various types, and higher education institutions - is to organise a number of factors in order to facilitate learning more systematically than would occur in natural settings. To achieve this, such systems provide direct teaching and study resources; they also try to coordinate less visible influences such as support from parents and others including peers. But there are several factors which may influence whether and how learning actually takes place. These include the location, timing, pace and style of teaching, together with the resources available, organisational rules and the curriculum adopted by teachers. Effective management of these factors is key to successful learning, and any attempt to 'liberate the learner' may not achieve the desired outcomes if it merely shifts the balance of control of activity from the expert teacher to the novice student. Students may not know enough about their learning to manage it effectively by themselves. It follows that if digital technology is to improve education, it must help students to manage their learning; this has implications for our current aspiration for 'involving everyone'.

\section{Framework for analysis}

In order to analyse this development in rationale from a pedagogical perspective, it will be necessary to adopt a framework which is sensitive to the detailed decisions and actions taken by teachers and learners when using ICT and other media as aids to learning. The terms affordance and constraint have been used widely to analyse how factors in the environment influence activity (see, for instance, [19] and [31]). Although they have been interpreted in various ways in the literature, there is enough similarity in the meanings to avoid the need for precise definition here. They are valuable tools for the analysis of educational activity, particularly where students carry out actions in pursuing certain goals which are generally set by the teacher. Learners have options concerning their actions in pursuit of these goals, and make decisions based on the affordances and constraints presented to them by the learning environment. Whilst some of the features of the activity setting will be fixed, many others can be manipulated, and the term orchestration has also been used widely over recent years to characterize the manipulation of the environment for learning [24].

At a general level, "orchestration refers to how a teacher manages, in real time, multi-layered activities in a multi-constraints context" [12]. More precisely, it concerns the purposeful arrangement of affordances and constraints for students' actions during a task in order to bring about learning from their actions [19]. It is not only the teacher who can orchestrate activity; learners themselves can manage their environment to some extent. Orchestration can range from teacher intervention during collaborative activity using tablets in a primary school mathematics lesson [24] to students seeking help from teaching assistants in a university Physics class [12].

Five key elements comprise the orchestration of learning: design/planning, regulation/management, adaptation/flexibility/intervention and awareness/assessment [24]. In a formal setting, whether in a classroom or online, a teacher will typically:

- design a task and plan the resources to be available to students

- discuss the concepts and techniques relevant to the task 
- give procedural instructions

- explain outcome expectations

- monitor student activity and intervene with individuals or groups: adding or changing resources, instructions or expectations; answering and asking questions; providing prompts and explanations

- evaluate outcomes, assess learning and provide feedback.

Students may also manipulate the affordances and constraints to help achieve the task goal, particularly by using peers to help explain ideas, clarify instructions and locate resources. This may inhibit the intended learning, however - for example if one student just copies the work of another or focuses merely on completing the task in the simplest manner [20].

An orchestration perspective provides a means of analysing the role of digital technology in learning and how it changes with increasing maturity and technological advance. In characterising how learners' actions are facilitated (the 'freedom to' aspect) together with how their actions are restricted (the 'freedom from' aspect), it offers a more sophisticated framework for studying the way in which learning is managed than the simple idea of balance of control.

\section{Liberating the learner}

The contributions to WCCE 1995 demonstrated a number of themes concerning the nature of digital technology and its effect on the balance of control of learning. The Working Group papers suggested empowerment of the individual student to learn outside the teacher's sphere of influence [29], and the emergence of new contexts for learning: home and other locations outside school [7]. Individual papers provided a variety of perspectives on how this might be achieved.

Several were concerned with the design of intelligent tutoring systems which combine expert systems, artificial intelligence engines and models of individual student behaviour to manage learner activity in an online task (for example [2]). Whilst this certainly had the potential to liberate the teacher, and to enable a small number of staff to manage a large number of students in many locations, the orchestration was only shifted as far as the computer system which essentially acted a surrogate teacher. Indeed, the design and planning stages still required an expert human teacher, and whilst the system may have been able to build up an extensive database concerning the knowledge and learning approaches of a large number of individual students, the adaptation and flexibility required for effective intervention proved much harder to achieve.

Other software environments were designed instead to facilitate learner control supported by structure for their activities (for example [11]. Although the orchestration within these environments was fully programmed in advance and hence the affordances and constraints could not generally be adapted by the teacher, they did allow more learner orchestration than most traditional classroom tasks. Furthermore, when they were used in a classroom, the teacher could carry out most of the elements of orchestration including dynamic intervention. Some software was designed to act as the learner's partner in an activity, providing the equivalent of peer orchestration as 
what was described as a "social machine" [13] or "social learning system" [10]. In other cases, the software took the role of a tool in a construction task (for example [33]) or searching large databases [16]; these applications required learner orchestration on a different level, requiring creativity, planning and a critical approach.

Although there was frequent reference to student-centred learning, only one contribution referred to a personal learning environment [18]. This was facilitated by each student having a notebook computer to be used in school and home. There was no mention at all of learning management systems, although one contributor [23] did give a foretaste of things to come in describing how the World Wide Web (still in its infancy in 1995) was used to provide material for students and allow them to communicate asynchronously with tutors.

\section{Discussion}

In 1995 there was clearly a desire to use digital technology to help give students more influence over learning situations. The theme of 'liberating the learner' was interpreted quite cautiously, but the idea that the teachers' control could and would diminish in the digital environment ran right through the contributions analyzed. Consequently most papers were concerned with how this more student-centered scenario might be implemented in terms of technological design. The focus on orchestration in the analysis has brought out a variety of ways in which the management of learning might be shared amongst different participants: teachers, students and the technology itself. The key issue for implementing technological assistance in any setting is not what the balance of control should be, but what contribution each of the participants can best make to the processes involved in orchestration. It did not seem in 1995 that technology was at the stage of making a large, active contribution to either design/planning, monitoring/intervention or assessment/feedback, and for most contributors it remained a tool and resource for the human agents involved.

Control over the course of learning activity involves orchestration of relevant affordances and constraints; if teachers are to delegate at least some of this and technology is not (yet) ready to take it on, then students need to have some skills in orchestration. However, to many educationists orchestration represents "the empowerment of teachers as drivers of classroom activities" [12], and it is not clear what might persuade teachers to relinquish any of this power. The contributors to WCCE 1995 did not really address this issue. Whilst WG3.1 [29] envisaged that "the teacher becomes a learning guide or a mentor for the students, cooperating with pupils in a learning experience” only a small number of papers [15], [22], [28] explicitly considered changes in the teacher's role. Most seemed to assume that a move from direct teaching of students to authoring of materials was unproblematic, and that the key challenge for technology was to provide an adequate model of the learner in order to sequence their tasks and provide resources. In contrast, perhaps, was the promise of improved collaboration between students afforded by new communications technology, and there were examples of how to meet the challenge of orchestrating video conferencing [14] and text conferencing systems [4] so as to promote learning. 


\section{Developments since 1995}

Looking now from 2017, what progress have we made in the use of digital technology to 'liberate the learner'? Examples of developments since 1995 which have made a substantial impact on teaching and learning, include:

- Learning management systems: these can be accessed anytime, anywhere but despite the name, they do not actually orchestrate learning themselves, but rather provide a structure and features which support management of resources by teachers but impose significant constraints on learners [6]. Whilst these have been embedded widely in higher education institutions, their adoption in schools has been much less than was anticipated a few years ago.

- Interactive whiteboards: these also provide many features which can afford and constrain classroom activity, but have been largely used by teachers to facilitate their traditional approaches to orchestrating resources and are valued for their effects on motivating learners (see, for example, [20]). These devices have been very widely adopted in schools, but have had less influence in higher education.

- Web2 and Social media: structures such as blogs, wikis, news broadcasting and social networking have all been appropriated widely for educational purposes; they have affordances for interaction over distance and time, but pose considerable challenges for distributing the orchestration between teachers and students [3], and perhaps because of this they do not yet seem to have been adopted widely in educational institutions.

- Mobile learning and 1-1 classroom devices: again, they clearly offer affordances for action which is flexible in place and time, and also for individualised learning. The distribution of orchestration is again a challenge, and although in many institutions it is the norm for each student to have a computer in the classroom, their use in schools is often tightly controlled by the teacher and students are not allowed to use their own devices because of potential distractions [32].

- Gamification: this approach represents a particular mode of orchestration in which the activity setting takes the form of a game in some way. The constraints are managed by the computer according to the rules of the 'game' and the affordances for action are orchestrated largely by the learners. Perhaps for this reason, game-based learning is seen as particularly motivating for students [8]. As the active role of the teacher may be quite small, it is particularly suitable for use outside the classroom.

In each of these cases, it seems that the degree of adoption of the technology in different sectors is directly correlated with the fit between the form of orchestration supported by the technology and the traditional pedagogy of the teacher. In other words, ICT is used when it helps the teacher to do what they already do. Clearly, advances in didactics have not kept pace with advances in technology; does this mean that the call for 'liberating the learner' is even more valid than 22 years ago?

In many parts of the world, most young people are now 'digital residents' who live their lives online. They perhaps feel liberated in that they can find resources for 
learning whenever they want to, but this may be a naïve illusion. People leave traces when they search the internet, particularly if they have social media profiles, and can be 'found' at any time by individuals and organisations wishing to steer them towards particular options in their searches. These organisations may have commercial - or perhaps more salacious - interests rather than educational purposes. A simple call for 'liberation' no longer seems to represent our aspirations for the learner's relationship with education when the orchestration of their environment is so widely distributed. Merely freeing learners from constraints imposed by the teacher, curriculum etc is unlikely to be fruitful when the affordances for action are so many and varied that orchestrating them become a massive challenge.

\section{Tomorrow's learning: 'involving everyone'}

The current theme envisages that in future, technology will enable us to 'involve everyone' in learning. Is this an appropriate aspiration? Involvement seems to require more than just access to teaching and resources; it suggests that our aim for all should be active participation in learning.

A number of contributors to WCCE 2017 addressed these issues. Some identified the nature of the task as an important factor in motivating learning. The creation of a worthwhile product was seen as particularly significant [30,34], particularly if this presented a challenge to learners [1], although such challenges must be seen as realistic targets by learners [25] and an alternative strategy involving finding, trying out and reflecting/discussing is also effective [32]. Digital technology can support game environments which engage learners actively with learning tasks within and beyond the classroom $[1,9]$ and increase students' interest in the learning process itself rather than just the grades achieved [1]. It can increase the 'learnability' of topics by positioning students positively in relation to difficult concepts [17]. Whilst a digital learning environment may be designed for active learning [34] or active participation [21], the affordances of the technology may not be sufficient on their own to sustain student engagement, and many learners need the support of the teacher or others, either in the classroom [25, 34] or online [21]. For learners accustomed to using technology on the move, physical activity with mobile devices outside the classroom also aids engagement in learning [32].

The idea of 'freedom' had not entirely disappeared; for some contributors, choice was seen as an important factor in involvement of learners. Being able to select a theme of personal interest to work on was motivating for students [30,34], although there was some concern that students might only be motivated by themes in which they were personally interested [21]. Freedom to use heuristic methods in problemsolving was supported by digital environments [30], a situation which is reminiscent of the vision for LOGO classrooms in the 1980s which had largely disappeared in 1995 [27] 


\section{Discussion}

The challenge of progressing from provision of access to teaching towards participation in learning can be informed by the analysis above. There is overwhelming evidence that digital technology motivates students to participate in activity; the difficulty comes in stimulating students to focus on learning from that activity. Teachers are generally adept at designing and preparing environments that offer affordances for all students in their charge, but we have noted that these environments are based largely on traditional pedagogy and may not exploit the full potential of the technology. The first stage in the development of active participation in learning involves being able to judge when digital technology can provide more or better affordances for learning rather than merely for task completion. But digital environments provide affordances for many other actions, and in order to avoid distractions, students must first adopt the teacher's intention, not just for task completion, but for achieving the intended learning outcomes.

The second stage is for students themselves to learn to orchestrate affordances and constraints for learning: this is the essence of 'intentional learning'. Effective learners do this already, but many students do not seek - or are prevented from using prompts from peers, new resources, or even the digital tools which are familiar from everyday life. Digital technology can support this sharing of orchestration (see, for example, [28] which in 1995 was already dealing with this idea explicitly) but some learners will need support from teachers or other people [25].

\section{Conclusion}

The key to liberating learners is giving them ability to participate actively through orchestrating resources for learning, but I have argued that in order to ensure involvement in learning, learners must also have an intention to learn from their activity. Learners' intentions may not be the same as those of their teachers, however, and however liberated or involved learners are, the questions remains concerning what they are learning. Traditional responses to students' lack of focus on the intended learning involve imposing constraints such as rules for classroom behavior. In the digital environment, similar constraints such as blocking access to websites and banning mobile devices are likely to be unsuccessful and indeed counterproductive because of the students' abilities to overcome such constraints. A better route to improved learning may be for teachers to shift their efforts towards supporting all students in using their abilities to orchestrate the affordances of the digital environment in pursuit of the intended learning in ways observed, for example, in [5]. An aspiration of 'involvement' rather than 'liberation' for the learner offers teachers a positive role in the learning process rather than having to relinquish their power.

Having analyzed the changes in aspiration for technology's role in education over the past 22 years, it is tempting to speculate about what we might aspire to in 2039. Where technology is concerned, it is very risky to speculate on developments far into the future. In any case, technology's application to education depends very much on whether schooling in institutions remains the dominant approach for compulsory education. Furthermore, education is always largely controlled by people who 
experienced compulsory education at least 20 years previously, educational methods change little from one generation to the next. Will the current cohort of school students be the ones to bring about the paradigm shift afforded by ubiquitous digital technology? If so, in 22 years' time, we may well need to focus less on how to involve learners and more on what is learned and who controls learning. Perhaps then the theme for 2039 will be 'Liberating the Learner' - again!

\section{References}

1. Algamdi, J. \& Holland, C.: Game-play: Effects of online gamified and game-based learning on dispositions, abilities and behaviours of primary learners. Paper presented at World Conference on Computers in Education - Tomorrow's Learning: Involving Everyone, Dublin (2017)

2. Arruarte, A., Fernandez-Castro, I.: A two-phased development shell for learning environments: a design proposal. In Tinsley, J. D., Van Weert, T. J. (eds.) Proceedings of the sixth IFIP World Conference on Computers in Education. Chapman \& Hall, London (1995)

3. ASHE: Limits to student engagement. ASHE Higher Education Report 40 (6),75-87

4. Austin, R.: Quality learning through computer conferencing. In Tinsley, J. D., Van Weert, T. J. (eds.) Proceedings of the sixth IFIP World Conference on Computers in Education. Chapman \& Hall, London (1995)

5. Barnes, J. \& Kennewell, S.: Investigating teacher perceptions of teaching ICT in Wales. Education and Information Technologies. 22(5), 2485-2497 (2017)

6. Bennett, S. Learning Management Systems: A Review. AUT University, Auckland (2011)

7. Benzie, D.: IFIP Working Group 3.5: using computers to support young learners. In Tinsley, J. D., Van Weert, T. J. (eds.) Proceedings of the sixth IFIP World Conference on Computers in Education. Chapman \& Hall, London (1995)

8. Caponetto, I., Earp, J. \& Ott, M.: Proceedings of the European Conference on Games Based Learning. Vol. 1, 50-57 (2014)

9. Carvalho, A. A.: Konnecting: a mobile game to introduce freshmen to the evolution of communication. Paper presented at World Conference on Computers in Education Tomorrow's Learning: Involving Everyone, Dublin (2017)

10. Chan, T.W., Lai, J. A.: Contest-Kid: a competitive distributed social learning environment. In Tinsley, J. D., Van Weert, T. J. (eds.) Proceedings of the sixth IFIP World Conference on Computers in Education. Chapman \& Hall, London (1995)

11. Cumming, G., Zangari, M., Thomason, N.: Designing software for cognitive change: StatPlay and understanding statistics. In Tinsley, J. D., Van Weert, T. J. (eds.) Proceedings of the sixth IFIP World Conference on Computers in Education. Chapman \& Hall, London (1995)

12. Dillenbourg, P.: Design for classroom orchestration. Computers and Education 69, 485492 (2013)

13. Dowling, C.: The 'social' machine: the computer as a participant in social and cognitive interactions within the classroom. In Tinsley, J. D., Van Weert, T. J. (eds.) Proceedings of the sixth IFIP World Conference on Computers in Education. Chapman \& Hall, London (1995) 
14. Evjemo, B., Eidsvik, A. K., Danielsen, T.: Cooperating school classes In Tinsley, J. D., Van Weert, T. J. (eds.) Proceedings of the sixth IFIP World Conference on Computers in Education. Chapman \& Hall, London (1995)

15. Frath, P. What context for liberated computer assisted language learning? In Tinsley, J. D., Van Weert, T. J. (eds.) Proceedings of the sixth IFIP World Conference on Computers in Education. Chapman \& Hall, London (1995)

16. Hammond, M.: Learning from experience: approaching the research of CD-ROM in schools. In Tinsley, J. D., Van Weert, T. J. (eds.) Proceedings of the sixth IFIP World Conference on Computers in Education. Chapman \& Hall, London (1995)

17. Jakab, C. \& Redman, C.: How interactives can change learnability of science concepts for young children - re-positioning them as learners 'who can and did'. Paper presented at World Conference on Computers in Education - Tomorrow’s Learning: Involving Everyone, Dublin (2017)

18. Jones, D.: The introduction of an information technology project: personal computing in the classroom. In Tinsley, J. D., Van Weert, T. J. (eds.) Proceedings of the sixth IFIP World Conference on Computers in Education. Chapman \& Hall, London (1995)

19. Kennewell, S.: Using affordances and constraints to evaluate the use of ICT in teaching and learning. Journal of Information Technology for Teacher Education. 10, 101-116 (2001)

20. Kennewell, S.,Tanner, H., Jones, S. and Beauchamp, G. Analysing the use of interactive technology to implement interactive teaching. Journal of Computer Assisted Learning, 24(1), 61-73 (2008)

21. Kolbaek, D. \& Nortvig, A-M.: An educational experience with online teaching - not a best practice. Paper presented at World Conference on Computers in Education Tomorrow's Learning: Involving Everyone, Dublin (2017)

22. McDougall, A., Cumming, G., Sussex, R.: Learner modelling by expert teachers: learner information space and the minimal learner model. In Tinsley, J. D., Van Weert, T. J. (eds.) Proceedings of the sixth IFIP World Conference on Computers in Education. Chapman \& Hall, London (1995)

23. Nott, M., Riddle, M., Pearce, J.: Enhancing traditional university science teaching using the World Wide Web. In Tinsley, J. D., Van Weert, T. J. (eds.) Proceedings of the sixth IFIP World Conference on Computers in Education. Chapman \& Hall, London (1995)

24. Prieto, L. P., Holenko-Dlab, M., Abdulwahed, M., Gutiérrez, I., \& Balid,W.: Orchestrating technology enhanced learning: a literature review and a conceptual framework. International Journal of Technology-enhanced Learning, 3(6), 583-598 (2011)

25. Saito, T.: Educational support on Computing and Informatics as means of empowering disadvantaged young people in developed countries. Paper presented at World Conference on Computers in Education - Tomorrow's Learning: Involving Everyone, Dublin (2017)

26. Sharples, M.: Shared orchestration within and beyond the classroom Computers and Education 69, 504-506 (2013)

27. Tagg, C., Tagg, B. \& Oram, I.: Realizing a vision? In Tinsley, J. D., Van Weert, T. J. (eds.) Proceedings of the sixth IFIP World Conference on Computers in Education. Chapman \& Hall, London (1995)

28. Turner, J.: Involving the school teacher in liberating the learner from traditional school culture. In Tinsley, J. D., Van Weert, T. J. (eds.) Proceedings of the sixth IFIP World Conference on Computers in Education. Chapman \& Hall, London (1995) 
29. Van Weert, T. IFIP Working Group 3.1: towards integration of computers into education. In Tinsley, J. D., Van Weert, T. J. (eds.) Proceedings of the sixth IFIP World Conference on Computers in Education. Chapman \& Hall, London (1995)

30. Wasif, N.: Creative coding with Scratch: presentation of the pilot project in primary school. Paper presented at World Conference on Computers in Education - Tomorrow's Learning: Involving Everyone, Dublin (2017)

31. Webb. M.: Affordances of ICT in science learning: implications for an integrated pedagogy. International Journal of Science Education, 27(6), 705 - 735 (2005)

32. Weigend, M.: Smartwalk: Computer science on the schoolyard. Paper presented at World Conference on Computers in Education - Tomorrow's Learning: Involving Everyone, Dublin (2017)

33. Wells, C.: Hypermedia authoring in the classroom: but what is required to make it really creative? In Tinsley, J. D., Van Weert, T. J. (eds.) Proceedings of the sixth IFIP World Conference on Computers in Education. Chapman \& Hall, London (1995)

34. Williams, L.: Involving everyone: Using the "Literacy from Scratch" project to develop the Computing and presentation skills of FE students with learning difficulties and disabilities (LLDD students), aged 18 to 24 years, and of their Learning Assistants. Paper presented at World Conference on Computers in Education - Tomorrow's Learning: Involving Everyone, Dublin (2017) 